\title{
A Bayesian Classification Approach for Mycobacterium Tuberculosis in Uttarakhand
}

\author{
Nidhi Puri \\ Asst.Prof, Dept. of Computer \\ Science \& Engineering \\ HNB Garhwal University \\ Srinagar (Garhwal)
}

\author{
Anubha Chauhan \\ Asst.Prof, Dept. of Computer \\ Science \& Engineering \\ HNB Garhwal University \\ Srinagar(Garhwal)
}

\author{
Naresh Dobhal \\ Asst.Prof, Dept. of Computer \\ Science \& Engineering \\ HNB Garhwal University \\ Srinagar (Garhwal)
}

\begin{abstract}
Medical data mining tools have dramatically impacted the health care industry by improving the diagnosis of medical. Tuberculosis is disease caused by bacteria, called Mycobacterium tuberculosis, TB usually attacks the lungs, but also bacteria can attack any part of the body such as kidney or brain. This Paper describes a method Bayesian classification for automated mycobacterium tuberculosis detection in tissues. Bayesian Classification approach is used to classify in 2 classes:-Pulmonary and Extra Pulmonary, Bayesian classification approach able to produce better performance with some input feature compared to the association method [7].
\end{abstract}

\section{Keywords}

Mycobacterium, Tuberculosis, Bayesian classification.

\section{INTRODUCTION}

Tuberculosis is one type of virus affected disease, caused by bacteria called Mycobacterium. Mycobacterium tuberculosis bacteria through microscopic analysis. There are 2 types of tuberculosis-

1) Pulmonary-When tuberculosis bacteria can settle in the lungs and begin to grow. TB in the lungs or throat can be infectious. They can move through the blood to other parts of the body.[8]

2) Extra Pulmonary-When TB bacteria can settle the other parts of the body such as bone, brain.

Tuberculosis bacteria are put into the air, when a person with active disease of the lungs or throat coughs and sneezs. People nearby May breathe in TB bacteria. Now in this paper we have applied bayes theorem and Bayesian classification theorem for tuberculosis detection.

\section{BAYES THEOREM}

Bayes theorem is named after Thomas Bayes. Let $\mathrm{X}$ be data tuples belongs to specified class c. For classification problems, $\mathrm{P}(\mathrm{H} \mid \mathrm{X})$, is the prior probability, of $\mathrm{H}$ conditioned on $\mathrm{X}$. In contrast, $\mathrm{P}(\mathrm{X} \mid \mathrm{H})$ is the posterior probability of $\mathrm{X}$ conditioned on $\mathrm{H}$. $\mathrm{P}(\mathrm{H}), \mathrm{P}(\mathrm{X} \mid \mathrm{H})$, and $\mathrm{P}(\mathrm{X})$ may be estimated from the given data. Bayes Theorem is useful in that it provides a way of calculating the posterior probability, $\mathrm{P}(\mathrm{H} \mid \mathrm{X})$, from $\mathrm{P}(\mathrm{H}), \mathrm{P}(\mathrm{X} \mid \mathrm{H})$, and $\mathrm{P}(\mathrm{X})$. Bayes Theorem is-[1]

$$
P(H \mid X)=\frac{P(X \mid H) P(H)}{P(X \mid H) P(H)+P(X \mid H) P(H)}
$$

Where $\mathrm{P}(\mathrm{H} \mid \mathrm{X})$ is called the posterior probability, while $\mathrm{P}(\mathrm{H})$ is the Prior probability associated with hypothesis $\mathrm{h} 1 . \mathrm{P}(\mathrm{X})$ is the probability of the occurrence or data value $\mathrm{Xi}$ and $\mathrm{P}(\mathrm{X} \mid \mathrm{H})$ is the conditional probability, that given a hypothesis.

\section{BAYESIAN CLASSIFICATION}

1. We need to maximize $\mathrm{P}\left(\mathrm{X} \mid C_{i}\right) \mathrm{P}\left(C_{i}\right)$, for $\mathrm{i}=1,2 \ldots \mathrm{n} \mathrm{P}($ $C_{i}$ ), the prior probability of each class, can be computed based on the training tuples: To Compute $\mathrm{P}\left(\mathrm{X} \mid C_{i}\right)$ for children.

2. Suppose that there are $m$ classes $c_{1}, c_{2} \ldots \ldots c_{m}$ Given a tuple, $\mathrm{X}$, the classifier will predict that belongs to the class having the highest posterior probability, conditioned on $\mathrm{x}$, That is, Bayesian classifier predicts that tuple $\mathrm{X}$ belongs to the class ci, if and only if-[10]

$\mathrm{P}\left(C_{i} \mid \mathrm{X}\right)>\mathrm{P}\left(C_{J} \mid \mathrm{X}\right)$ for $1<\mathrm{j}<\mathrm{m}, j \neq i$

By bayes theorem-

$P\left(C_{i} \mid X\right)=\frac{P\left(X \mid C_{i}\right) P\left(C_{i}\right)}{P(X)}$

3. $\mathrm{P}(\mathrm{X})$ is constant for all classes, only $\mathrm{P}\left(\mathrm{X} \mid{ }_{i}\right) \mathrm{P}\left(C_{i}\right)$ need be maximized. if the class prior probabilities are not known, that it is commonly assumed that the classes are equally likely, that is, $\mathrm{P}\left({ }^{c_{1}}\right)=\mathrm{P}\left({ }^{c_{2}}\right)=\ldots \ldots . . \mathrm{P}(\mathrm{Cm})$, and we would therefore maximize $\mathrm{P}\left(\mathrm{X} \mid{ }^{C_{i}}\right) \mathrm{P}\left({ }{ }_{i}\right)$.[3]

4 .Given data sets with many attributes, it would be extremely computationally expensive to compute $\mathrm{P}\left(\mathrm{X} \mid{ }^{C_{i}}\right)$.In order to reduce computation in evaluating $\mathrm{P}\left(\mathrm{X} \mid C_{i}\right)$, then conditional independence is made.[11]

5. Given data sets with many attributes, it would be extremely computationally expensive to compute $\mathrm{P}\left(\mathrm{X} \mid{ } C_{i}\right)$.In order to reduce computation in evaluating $\mathrm{P}\left(\mathrm{X} \mid{ }_{i}\right)$, then conditional independence is made.[11]

$\mathrm{P}($ patient $)=\mathrm{X}$ ray $=\mathrm{Positive}=75 / 465=0.1612 j \neq i$

$\mathrm{P}($ patient $)=\mathrm{X}$ ray $=$ Negative $=50 / 465=0.1075$

We need to maximize $\mathrm{P}\left(\mathrm{X|}{ }^{C_{i}}\right) \mathrm{P}\left({ }{ }_{i}\right)$, for $\mathrm{i}=1,2 \ldots \mathrm{n} \mathrm{P}\left(C_{i}\right.$ ), the prior probability of each class, can be computed based on the training tuples- 
To Compute $\mathrm{P}\left(\mathrm{X} \mid C_{i}\right)$ for children-

If $(\mathrm{P}($ age $=$ child $\mid$ category $\mathrm{I}=$ Negative $))$

$=15 / 1=15$

Else If $(\mathrm{P}($ age $=$ child $\mid$ category II $=$ Negative $))$

$=15 / 2=7.5$

Else $(\mathrm{P}($ age $=$ child $\mid$ category III $=$ Positive $))$

$=15 / 3=15$

To Compute $\mathrm{P}\left(\mathrm{X} \mid C_{i}\right)$ for youth-

If $(\mathrm{P}($ age $=$ youth $\mid$ category $\mathrm{I}=$ Negative $)$

$=50 / 1=50$

ElseIf $(\mathrm{P}($ age $=$ youth $\mid$ categoryII $=$ positive $))$

$=50 / 2=25$

Else $(\mathrm{P}($ age $=$ youth $\mid$ categoryIII $=$ Negative $))$

$=50 / 3=16.6$

To compute $\mathrm{P}\left(\mathrm{X} \mid C_{i}\right)$ for old category-

If $(\mathrm{P}($ age $=$ old $\mid$ category $\mathrm{I}=$ positive $)$ )

$=75 / 1=75$

ElseIf $(\mathrm{P}($ age $=$ old $\mid$ category $I I=$ negative $))$

$=75 / 2=37.5$

Else $(\mathrm{P}($ age $=$ old $\mid$ categoryIII $=75 / 3=25))$

Using the above probabilities, we obtain-

$\mathrm{P}(\mathrm{X} \mid$ Diagonsis $=$ Positive $)=\mathrm{P}(0.1612)(5 * 25 * 75) *$

$\mathrm{P}(0.107)(15 * 50 * 37.5) * \mathrm{P}(0.107)(75 * 16.6 * 25)$

$=(1511.25) *(3009.375) *(3330.375)$

$=1.51462$

\section{GAIN RATIO}

The information gain measure is biased toward tests with many outcomes. That is it prefers to select attributes having a large number of values. Let node $\mathrm{n}$ represent or hold the tuples of partition D. The attribute minimize the information needed to classify the tuples in the resulting partitions and refers the least randomness.[4]

The expected information needed to classify a tuple in D is given by-

$$
\operatorname{Info}(D)=-\sum_{i=1}^{m} p_{i} \log _{2}\left(p_{i}\right)
$$

Where Pi is the probability that an arbitrary tuple in D belongs to class ci and is estimated by $\left|C_{i}, D\right| /|D|$.A $\log$ function to the base 2 is used, because the information is encoded in bits. Info (D) is just the average amount of information needed to identify the class label of a tuples in D.

Now, suppose we were to partition the tuples in D on some attribute $\mathrm{A}$ having $\mathrm{v}$ distinct values $\left\{a_{1}, a_{2} \ldots a_{v}\right\}$, as observed from the training data. If $\mathrm{A}$ is discrete-valued, these values correspond directly to the $\mathrm{v}$ outcomes of a test on $\mathrm{A}$. Attribute $\mathrm{A}$ can be used to split $\mathrm{D}$ into $\mathrm{v}$ partitions or subsets, $\left\{D_{1}, D_{2} \ldots \ldots, D_{v}\right\}$, where $D_{j}$ contain those tuples in D that have outcome $\mathrm{a}_{\mathrm{j}}$ of A. These partitions would correspond to the branches grown from node $\mathrm{N}$. The amount is measured by- [12]

$$
\operatorname{Info}_{A}(D)=\sum_{j=1}^{v} \frac{\left|D_{i}\right|}{|D|} * \operatorname{Info}\left(D_{j}\right)
$$

The term $|\mathrm{Dj} /| \mathrm{D} \mid$ acts as the weight of the Jth partition. Info (D) is the expected information required to classify a tuple from $\mathrm{D}$ based on the partitioning by A.[5]

Information gain is defined as the difference between the original information requirements (based on just the proportion of classes) and the new requirement (obtained after partitioning on A), That is,

Gain $(\mathrm{A})=\operatorname{Info}(\mathrm{D})-\operatorname{Info}_{A}(D)$

Suppose partition the tuples in $\mathrm{D}$ on some attribute A having $\mathrm{n}$ distinct values $\left\{a_{1}, a_{2} \ldots a_{v}\right\}$ for children-

$$
\begin{aligned}
\text { Info }(\mathrm{D}) & =-15 / 3 \log (15 / 3)-2 / 3 \log (2 / 3) \\
& =-5 \log (5)-0.66 \log (0.66) \\
& =-5(0.6989)-0.66(-0.1804) \\
& =-3.4948-+0.119064 \\
& =3.3757
\end{aligned}
$$

Ex-Table for Tuberculosis Patients, Divided into different Classes.

\begin{tabular}{|c|c|c|c|}
\hline ID & Age & Category & $\begin{array}{c}\text { Diagnosis } \\
\text { Class }\end{array}$ \\
\hline 1 & $1-15$ & 3 & $\mathrm{H} 3$ \\
\hline 2 & $15-30$ & 2 & $\mathrm{H} 2$ \\
\hline 3 & $30-45$ & 2 & $\mathrm{H} 2$ \\
\hline 4 & $45-60$ & 2 & $\mathrm{H} 2$ \\
\hline 5 & $60-75$ & 3 & $\mathrm{H} 1$ \\
\hline
\end{tabular}

The expected information needed to classify a tuples are partitioned according to age-

Infoage $(\mathrm{D})=15 / 3 *(-10 / 3 \log 10 / 3-5 / 3 \log 5 / 3+15 / 3 *(-$ $15 / 3 \log 15 / 15-0 / 3 \log 0 / 3)+15 / 3 *(-5 / 3 \log 5 / 3-10 / 3 \log 10 / 3)$

$=3 *(-(3.33) *(0.5224)-(1.666) *(0.220)$

$=3 *(-1.739592-0.3652)$

$=3 *(-2.1047)$

$=-6.3141$

Hence the gain information from such a partitioning would be-

$$
\begin{aligned}
\text { Gain (age) } & =\text { Info }(D)-\text { Infoage }(D) \\
& =15 / 3(1.66 \log (1.66)-3.33 \log (3.33) \\
& =15 / 3(1.66(0.220)-3.33 *(0.5224) \\
& =15 / 3(0.3652-3.33 *(0.5224) \\
& =3(0.3652-1.7395) \\
& =3(-1.3745) \\
& =-4.1235 \\
\text { Info (D) } & =-6.3141-4.1235 \\
& =-10.4376
\end{aligned}
$$




\section{HEURISTIC METHOD FOR CLASSIFICATION}

We have used greedy search algorithm for Heuristic method. For this method firstly we create Classification tree. In particular, we use an algorithm that begins by making the assumption that a node has no parents, and then adds incrementally that parent whose addition most increases the probability of the resulting structure [9]. When the addition of no single parent can increase the probability, we stop adding parents to the node. Researchers have made extensive use of similar greedy-search methods in classification systems [6].

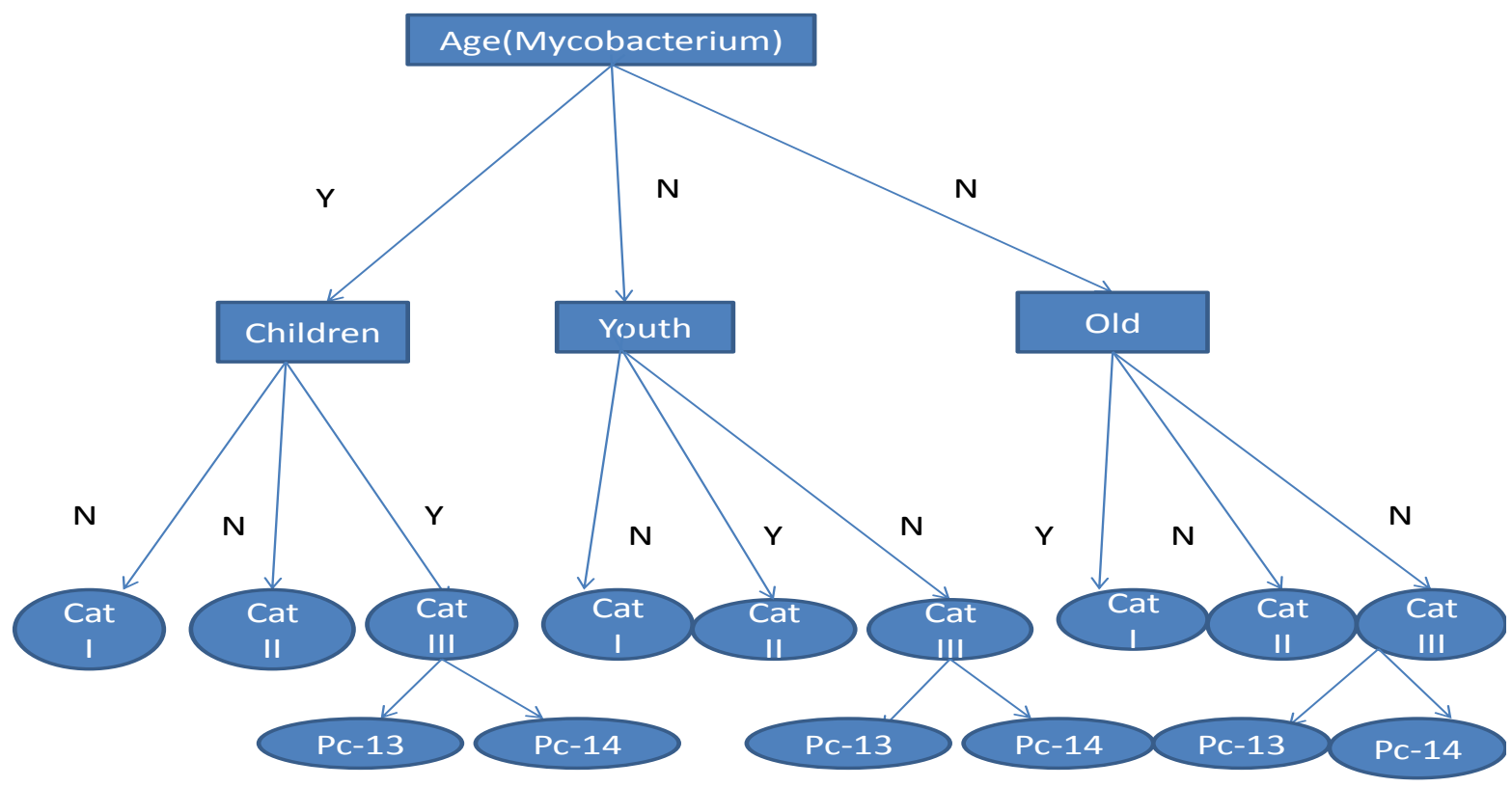

Fig 1: Classification Tree for Tuberculosis Patient

We shell use following fuction for Heuristic Method -

$$
g\left(i, \pi_{i}\right)=\prod_{j=1}^{q_{i}} \frac{\left(r_{i}-1\right) !}{\left(N_{i j}+r_{i}-1\right) !} \prod_{k=1}^{r_{i}} N_{i j k} !
$$

$=(2-1) ! 5 ! 5 ! /(10+2-1) *(2-1) ! 1 ! 4 ! /(5+2-1) ! *(2-$

1)! $4 ! 1 ! /(5+2-1) !^{*}(2-1) ! 0 ! 5 ! /(5+2-1) *(2-1) ! 4 ! 1 ! /(5+2-1)$ !

$=\left(1 !^{*} 5\right.$ !*5!/11!)*(1!*4! $\left.1 ! / 6 !\right) *(1 ! 4 ! 1 ! / 6 !) *(1 !$

$0 ! 5 ! / 6 !) *\left(1 !^{*} 4 !^{*} 1 ! / 6 !\right)$

$=1 * 120 * 24 * 24 * 24 / 3991680$

$$
\begin{aligned}
& =4.15 * 10^{-3} \\
& =(1 ! * 5 ! * 5 ! / 11 !) *(1 ! * 4 ! 1 ! / 6 !) *(1 ! 4 ! 1 ! / 6 !) *(1 ! 0 ! 5 ! / 6 !) * \\
& (1 ! * 4 ! * 1 ! / 6 !) \\
& =1 * 120 * 24 * 24 * 24 / 3991680 \\
& ==4.15 * 10^{-3}
\end{aligned}
$$

\section{RESULTS}

After applying Bayes theorem on Tuberculosis data taken from "Government Combined Hospital Srinagar (Garhwal) from 2001 to 2012" and then find out the results as follows-

\section{Results}

\section{Download information}

Workbook information

Number of sheets

Selected sheet

Sheet1

Sheet size

Dataset size

\section{Data source processing}




\section{Dataset Description}

\begin{tabular}{|c|c|c|c|}
\hline & Attribute & $\begin{array}{c}\text { Categor } \\
\mathbf{y}\end{array}$ & $\begin{array}{l}\text { Informati } \\
\text { on }\end{array}$ \\
\hline Year & & Discrete & 4 values \\
\hline Date & & $\begin{array}{l}\text { Continu } \\
\text { e }\end{array}$ & - \\
\hline Region & & Discrete & 3 values \\
\hline Age & & $\begin{array}{l}\text { Continu } \\
\mathrm{e}\end{array}$ & - \\
\hline sex & & Discrete & 2 values \\
\hline X-Ray & & Discrete & 1 values \\
\hline Diagnosis & & Discrete & 2 values \\
\hline Category & & $\begin{array}{l}\text { Continu } \\
\mathrm{e}\end{array}$ & - \\
\hline
\end{tabular}

\begin{tabular}{|l|r|r|r|}
\hline \multicolumn{1}{|c|}{ Values } & Count & \multicolumn{1}{c|}{ Percent } & Histogram \\
\hline Tehri & 76 & $8.2 \%$ & \\
\hline Srinagar & 234 & $74.19 \%$ & \\
\hline Pauri & 133 & $22.58 \%$ & \\
\hline
\end{tabular}

\begin{tabular}{|l|r|r|r|}
\hline \multicolumn{1}{|c|}{ Values } & Count & \multicolumn{1}{c|}{ Percent } & Histogram \\
\hline M & 320 & $61.29 \%$ & \\
\hline F & 180 & $38.71 \%$ & \\
\hline
\end{tabular}

X-Ray0.1748

\begin{tabular}{|l|r|r|r|}
\hline \multicolumn{1}{|c|}{ Values } & Count & Percent & \multicolumn{1}{c|}{ Histogram } \\
\hline Positive & 420 & $80.32 \%$ & \\
\hline Negative & 80 & $19.68 \%$ & \\
\hline
\end{tabular}

Diagnosis0.3122

\begin{tabular}{|l|r|r|l|}
\hline \multicolumn{1}{|c|}{ Values } & Count & \multicolumn{1}{c|}{ Percent } & Histogram \\
\hline Pulmonary & 325 & $80.65 \%$ & \\
\hline Extra Pulmonary & 75 & $19.35 \%$ & \\
\hline
\end{tabular}

Category0.6139

\begin{tabular}{|l|r|r|r|}
\hline \multicolumn{1}{|c|}{ Values } & Count & \multicolumn{1}{c|}{ Percent } & Histogram \\
\hline II & 210 & $49.13 \%$ & \\
\hline III & 185 & $38.48 \%$ & \\
\hline
\end{tabular}


$\underline{\text { Histogram Diagram for tuberculosis data }}$

\section{Data source processing \\ Computation time $15 \mathrm{MS}$ \\ Allocated memory $45 \mathrm{~KB}$}

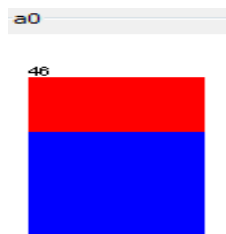

a4

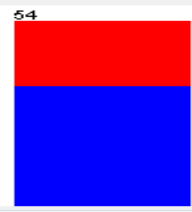

as
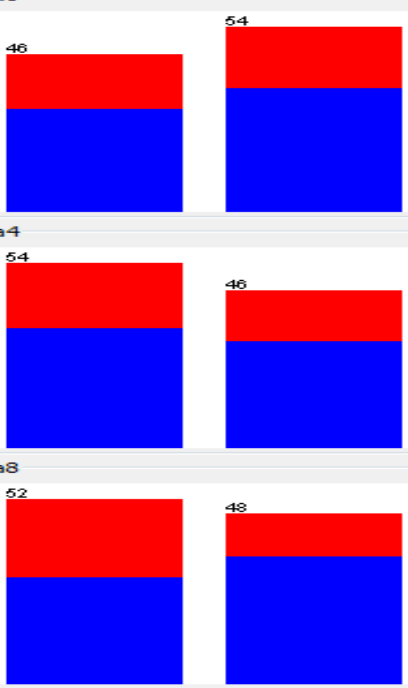

In this diagram red colour shows total tuberculosis patient in Uttarakhand State find out from "2001 to 2010" and blue colour shows those people are not affected by tuberculosis.

\section{CONCLUSION}

Now In this Paper we have taken Tuberculosis data, and then apply Bayesian Classification technique by the help of heuristic algorithm and greedy search method. The system extracts hidden knowledge from a historical tuberculosis disease database from 2001 to 2010 . This is the most effective method to predict patients with Tuberculosis disease. Continuous data can be used instead of just categorical data. By analysis of 10 years data we can find out that computation time $15 \mathrm{~ms}$ and allocated memory 45KB.By applying Bayesian classification technique and heuristic algorithm, we find out that maximum tuberculosis patient find out in Srinagar(Garhwal).

\section{ACKNOWLEDGMENTS}

The authors wish to thanks to Dr. A. K. Chaubey, Dr. S. Kotiyal, Dr. G. Pujari from "Government Combined Hospital Srinagar(Garhwal)", who has participated in this study and permission to carry out work.

\section{REFERENCES}

[1] Cooper, G.F. \& Herskovits, E.H. (1991). A Bayesian method for the induction of probabilistic networks from data (Report SMI-91-1). Pittsburgh PA: University of Pittsburgh, Section of Medical Informatics. (Also available as Report KSL-91-02, from the Section on Medical Informatics, Stanford University, Stanford, CA.)

[2] R. G. Cowell, A. P. Dawid, S.L. Lauritzen. Probabilistic Networks and Expert Systems.Springer Verlag. (1999)

[3] F.V. Jensen. Bayesian Networks and Decision Graphs. Springer Verlag. (2001)

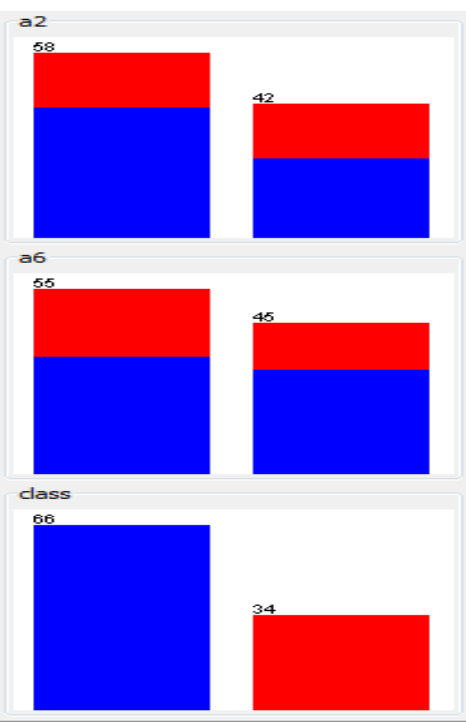

[4] N. Freidman, D. Geiger, S. Goldszmidt, Bayesian Networks classifiers. Machine Learning,29 (pp 131-161), (1997)

[5] M. Martinez-Morales, an Algorithm for the Induction of Probabilistic Networks from Data. XII Reunion Nacional de Inteligencia Artificial, ITESM, Cuernavaca, Morelos, Mexico, Limusa. (1995).

[6] J. Han, and M. Kamber, Data Mining. Concepts and Techniques, Morgan Kaufmann,(2001).

[7] G. F. Cooper, An Overview of the Representation and Discovery of Causal Relationships using Bayesian Networks. Computation, Causation \& Discovery. C. Glymour and G. F. Cooper, AAAI Press / MIT Press: $3-$ 62. (1999).

[8] S. Sharma, and A. Mohan, 'Extra pulmonary tuberculosis', Indian Journal of Medical Research, 120, pp. 316-353. 2004

[9] Lucas, P. J. F., van der Gaag, L. C., Abu-Hanna, A.: Bayesian networks in biomedicine and health-care. Artificial Intelligence in Medicine 30 (2004) 201-214

[10] Jiawei Han and Micheline kamber,Data Mining Concepts and Techniques.

[11] J. Kamerbeek and L. Schouls and M. Van Agterveld and D. Van Soolingen and A. Kolk and S. Kuijper and A. Bunschoten and R. Shaw and M. Goyal and J. Van Embden, Simultaneous detection and strain differentiationof mycobacterium tuberculosis for diagnosis and epidemiology, J. Clin. Microbiol.,1997.

[12] M. Sebban and I. Mokrousov and N. Rastogi and C. Sola, A data-mining approach to spacer oligonucleotide typing of Mycobacterium tuberculosis, Bioinformatics, No. 18, pp. 235-243, 2002. 